\title{
When Cultural Assumptions about Texts and Reading Fail: Teaching Talmud as Liberal Arts
}

\section{Elizabeth Shanks Alexander}

Чow do undergraduates with superficial or no previous exposure to Judaic texts learn to read the Talmud in translation within the context of a liberal arts education? This question has actively shaped my teaching of Introduction to Talmud at the University of Virginia since I first offered the course in 2001. Students opt to take this course for all sorts of reasons, which range from a genuine and enduring interest in the topic to purely pragmatic considerations (e.g., it helps them fulfill a requirement and fits their schedule). Typically, $15-25 \%$ of students enrolled in the course are Jewish. Most of the other students come from Christian denominations, many with a strong sense of religious identity.

When teaching the course initially, as their instructor, I assumed the most important service I could provide was cultural translation. Having invested considerable energy in identifying, describing, and analyzing the Talmud's repertoire of argumentational and interpretive moves, I felt my greatest asset as a teacher was the ability to explain talmudic dialectic in language and concepts familiar to my students. Students from early iterations of the course had helpfully pointed out that they would have liked it if I had done more than explicate the Talmud in plain language. They explained that they were not enthusiastic about investing time and energy in the difficult task of learning how to read Talmud, without clarity about why they should care to read Talmud in the first place. As I have revised the course over the years, I have experimented with different ways to emphasize the 
Talmud's relevance-for Jewish culture writ large, but also for them, whomever they may be, Jewish or not, religious in any tradition or not. I want my students to feel positively invested in the task of reading Talmud, enough so that they stay with it, challenges and setbacks notwithstanding.

This past semester, I experimented with a new way to make Talmud study more compelling in the context of a liberal arts education. I styled the students as partners in the instructional process. I made them responsible for monitoring their own successes and failures and the pace of their development as readers of Talmud. I drew on some of L. Dee Fink's work, which I had read during an intensive summer workshop on course design several years ago. He argues that significant learning experiences have six basic components. They provide opportunities and encourage students to: (1) understand foundational knowledge; (2) apply that knowledge; (3) integrate course materials with other disciplines, perspectives, and subject matter; (4) learn about oneself and others (the human dimension); (5) care about the subject matter, and (6) learn how to learn.

Fink emphasizes that the six components of significant learning experiences are not mutually exclusive. Rather, "each kind of learning is related to the other kinds of learning and ... achieving one kind of learning simultaneously enhances the possibility of achieving the other kinds of learning. ... For example, if a teacher finds a way to help students learn how to use the information to solve certain kinds of problems effectively (application), this makes it easier for them to get excited about the value of the subject (caring)." My course seeks to facilitate all components of significant learning experiences, but this past semester, I was particularly drawn to the sixth component (learning how to learn). This emphasis led me to design assignments asking students to reflect on and take responsibility for parts of the learning process. I hoped that these assignments would focus students' attention on the "how" of their reading practices and give them an opportunity to consider their effectiveness when engaging talmudic texts. This shift in pedagogic emphasis provided an interesting "hook" for the students, motivating them to work with material that was difficult and unfamiliar, even when they were manifestly discouraged, as is inevitable with beginning students of Talmud.

1 L. Dee Fink, Creating Significant Learning Experiences: An Integrated Approach to Designing College Courses (San Francisco: Jossey-Bass, A Wiley Imprint, 2003), 32; see also ibid, "A Taxonomy of Significant Learning," 27-59. 


\section{Assignments Focused on "Learning How to Learn"}

In past versions of my course Introduction to Talmud, writing assignments required students to practice the tasks and drill the skills reviewed in class. For example, following a unit that presents strategies for making sense of midrashic passages, students wrote a paper demonstrating their ability to perform this task independently, using passages not discussed in class. Such an assignment emphasizes components 1 and 2 of Fink's taxonomy. Students use concepts and vocabulary presented in class (foundational knowledge) to read a midrashic passage (application). When teaching the course this time, I retained some assignments emphasizing components 1 and 2 from prior years, but I also included newly designed assignments that required students to reflect on aspects of the learning process.

In one new assignment, students were required to write a weekly 200 to 300 word posting for our class blog, to be read by their class peers and me (people outside the class did not have access to the class blogsite). The assignment was designed to alert students to the many steps involved in learning to read something as manifestly difficult and unfamiliar as Talmud. I wrote prompt questions to guide them when they sat down to compose the blog posts. The questions were designed to accomplish two things. First, I wanted to draw students' attention to various aspects of the reading experience so that they could reflect on which strategies they found to be more effective and which were less so when engaging talmudic texts. Second, I wanted to nudge them gently toward strategies that I thought would serve them well when engaging these texts. Students had the freedom to respond to whichever prompt they felt would be most generative in a given week.

Below are the prompts that I gave the students; each is followed by a brief commentary about the pedagogical motivations for these prompts:

1. What was confusing, counterintuitive, or simply opaque to you from the reading? Where and why do you think the breakdown in understanding occurred? What is it about the text that makes it hard for you to understand? Alternatively, what makes you a less-than-ideal recipient of the text's meaning? 
The first question in this prompt reflects my view that effective learning occurs when students focus on rather than skim over difficulties. Students may be tempted to ignore the discomfort of not understanding something in the hope that the feeling will soon pass. At some point in the middle of the semester, I realized that students experience mild shame when they do not understand course materials. This prompt creates a space within the learning process for experiencing failure without shame. I want students to recognize that I do not expect them to succeed the first time or all the time and that frustration can be a source of insight. Their "failures" may actually guide them toward future success. The follow-up questions in this prompt encourage students to reflect on the reasons for their difficulty. The last question (What makes you a less-than-ideal recipient?) helps students recognize that their assumptions about the goals and process of reading may impede their success with Talmud, a book that comes from a culture very different from their own. I want students to recognize that culturally conditioned assumptions about what reading is and how it is done can impact reading outcomes.

2. Summarize what you take to be the key point of the assigned secondary source. Be generous in your reconstruction of the author's internal logic. How does the article help you make sense of the primary texts? What "tip" or "trick" can you glean from it?

This prompt is designed to communicate the value of secondary sources in the project of learning to read Talmud. The prompt steers students toward the "tips" and "tricks" within the article that will help them make sense of the primary texts. Each in-class lecture introduces students to a feature of talmudic discourse (e.g., Mishnah's tendency to arrange traditions topically and obscure the biblical roots of the legal tradition) and showcases one or more illustrative examples of this feature. This second prompt encourages students to anticipate the lecture and "teach themselves" what to look for and what to regard as significant in the primary source selections.

3. Reflect on your reading process. What was the first thing you did when you encountered the primary text? What did you do next? Which steps were more effective and which were less? Was there a certain point at which the text started to make sense? When and why? 
Alternatively, did the text never make sense? Why do you think that happened?

This set of questions expands on a theme from the first prompt, namely, that how one reads is culturally conditioned. The questions help students identify the assumptions that govern their own reading practice by tuning in to what they actually do when they sit down to read. The questions promote heightened awareness of the concrete ways in which students interact with texts. Additionally, the questions prompt an evaluative process in which the students distinguish between more and less successful approaches to reading the text.

4. Tell us about a detail that caught your eye in a primary text. What makes this detail compelling and noteworthy? What does it reveal about the text's commitments, concerns, or resolutions? Why does it resonate with you?

The fourth prompt offers students a specific strategy to employ when interacting with talmudic texts - asking them to focus on a concrete detail. Over the years, I have observed that students naturally gravitate toward some reading strategies over others. It is not uncommon for students to accord greater importance to the general themes of a text than to specific details featured in the text. While gathering-up general themes and trends is important, reading for generalities has limited utility when interacting with talmudic texts, which typically are structured around very specific questions and numerous textual details. This prompt encourages students to allow specific textual details, rather than overarching themes, to guide the reading experience.

In addition to the weekly blog post, a second assignment was inspired by the goal of helping students "learn how to learn." In the final paper, I asked students to narrate their development as a reader of Talmud over the course of the semester. I directed them to address the following issues in their narrations:

1. What is the difference between how you approached these texts at the beginning of the semester and how you approach them now? What were you engaging in the texts initially? What do you notice now? What did you expect of yourself then and now? What were key moments of insights for you? Which insights led to other insights? 
2. What did you learn about yourself as a reader? Are the skills you gained in the process of learning to read Talmud transferrable? If yes, how are they transferrable? If not, why?

3. Which reading had the most impact on you? Which class discussion? Which blog post felt most like a breakthrough?

Students were instructed to illustrate moments of key insight with reference to specific primary texts. The requirement that students cite and discuss specific primary texts ensured that my focus on the sixth component of Fink's taxonomy (learning how to learn) did not come at the expense of more traditional pedagogical goals, generally understood in terms of the first two components of the taxonomy (foundational knowledge and application). Students would have to demonstrate competence in reading texts in order to narrate the process by which they came to be able to do so.

Two distinct concerns led me to design these assignments. First, as I have already explained, I wanted to provide students with a forum in which the process of learning itself would be a focal point. I hoped that incorporating a "learning how to learn" component into the course would increase students' integration of the course content, as per Fink's suggestion that different kinds of learning mutually reinforce each other. Ideally, having students focus on the process of learning to read would also help them (1) master foundational knowledge central to Talmud study, (2) apply that knowledge to the reading of texts, (3) develop a new passion for Talmud study or strengthen an existing one, (4) reflect on connections between Talmud study and other subjects, and (5) ultimately, learn something about themselves.

My second motivation in developing the new assignments was to provide a source of data (in the form of student testimonials) for my reflection on the process whereby my students were learning to read Talmud. In the body of this chapter, I report on two themes that emerged as I reviewed, sifted through, and synthesized the students' blog posts and final papers. One trope that returned in various ways concerns the manner in which students focus their attention when reading. Their natural tendency seems to have been to read with the goal of perceiving an overarching narrative, or a general sense of the whole. Students reported that this approach to reading led to frustration when working with talmudic texts. Over the course of the semester, they realized 
that they needed to shift their focus from the big picture to textual details in order to read talmudic texts effectively. A second prevalent theme is best understood in terms of students' underlying assumption about what texts are and what they do. Students' natural tendency here seems to have been to regard texts as things. When texts are understood in this manner, the goal of reading is to grasp or hold the "thing." That is, students want to know what the text "is" - what it claims or what it means. In order to become successful readers of Talmud, students reported having to learn to regard the texts differently, namely, as providing access to a "thinking process." Students found that the texts made much more sense to them when they read them in order to experience the thought process that lies behind them. That is, they succeeded as readers when they understood the act of reading as a means to reproduce and experience anew the thoughts and arguments of the talmudic sages. In this new paradigm, reading prompts an experience of thinking and arguing.

It appears that culturally conditioned ideas about texts and reading shaped what they did when they sat down with a text, what they looked for when reading, and what they expected to gain from interacting with a text. Data from this course, then, suggests that one can maximize students' success if one encourages them first to observe their instinctive and culturally conditioned ways of interacting with texts, and subsequently to modify them. When students become aware of their natural patterns of engaging texts, they strengthen their capacity to intervene deliberately and adopt a set of learned practices better suited to Talmud.

\section{My Goal for the Students}

I measured my students' success as readers of Talmud by their ability to read, understand, and explain the back and forth of a complex dialectical argument by semester's end. I did not expect my students to be able to achieve understanding independently; rather, I wanted them to be able to follow my explanations of the material to the extent that they could accurately explicate the text in their own words. The choice to emphasize competency in reading halakhic passages, rather than aggadic, reflects my desire to equip students to make sense of the Talmud's overarching discursive framework. I do not want my students to experience Talmud as a series 
of disconnected aphorisms or sage stories, though these genres offer significant insight into the thought world of the talmudic sages. Rather, I want students to be able to make sense of the Talmud as a genre of literature. By familiarizing them with dialectical interests, devices, and movements that reappear throughout the Talmud, I am giving students tools to enter the Talmud's meandering conversations on any page, provided they receive guidance in the specific topics treated.

Rava and Abaye's discussion of yeush shelo midaat (see my translation of this phrase below) centers on the question of whether the owner of an object needs to be aware of having lost it in order for the object to become "ownerless." A lost object's status as ownerless determines the finder's rights and obligations with respect to the object. If a lost object is ownerless, the finder becomes its legal owner. If the object is not ownerless, the finder must advertise the find so that the owner may claim the object, as it still belongs to him. In order for the lost object to become ownerless, the original owner must despair of having it returned to him. The question that the sugya deals with is whether an object can become ownerless in the interval between when the owner loses the object and he becomes aware of his loss. If such a lost object is considered ownerless, the finder may keep it. If it is not considered ownerless, the finder may not.

Rava and Abaye agree that when the owner is aware of his loss he despairs of its return, the lost object becomes ownerless, and the finder may keep it. They disagree in the case of an owner who is not aware of his loss. Being unaware of his loss, the owner cannot despair of retrieving it. Abaye says that when the owner is unaware of his loss, the original owner retains ownership rights, and the finder does not become the object's new owner. Rava has a different approach. Confident that the owner will eventually become aware of the loss and despair of its return, Rava invents the concept of yeush shelo midaat (despair without [conscious] knowledge). This concept allows Rava to regard the lost object as ownerless at the moment that the finder discovers it, even though the owner has not yet consciously despaired of retrieving it. Since the object is ownerless when the finder discovers it, he becomes its rightful owner. Rava uses the concept of yeush shelo midaat to grant ownership to the finder in cases where the owner is not aware of his loss when the finder discovers it. 
Abaye, on the other hand, disallows the concept of yeush shelo midaat and argues that the finder takes legal possession only when the owner actually despairs of retrieving the object.

In this sugya, Rava and Abaye bring authoritative sources (mishnayot, baraitot, and halakhic midrash) to support their respective positions on the concept yeush shelo midaat. We read this argument on the last two days of class. In order to follow the argument, students needed to have mastered an extensive body of knowledge and skills. They need to be able to:

1. Identify and distinguish among different textual strata within the sugya (tannaitic, amoraic, and stammaitic)

2. Understand how mishnayot, baraitot, and halakhic midrash are interpreted to support the respective positions of Rava and Abaye

3. Recognize that the tannaitic sources cited in the sugya can be legitimately understood in more than one way

4. Understand some fine points of Jewish law, such as the difference between ownership and being a guardian for the owner

5. Grasp that the point of the argument is not to adjudicate between the two positions, but to appreciate how each sage uses the same authoritative sources to support his own position

Reading this sugya serves as a wonderful culminating exercise for the students. In order to do a successful reading of the argument, students need to have mastered and integrated terms and concepts from throughout the course, as the above skill list illustrates. Gratifyingly, the students' final blog posts ${ }^{2}$ reflect many feelings of accomplishment at the semester's end. Georgia ${ }^{3}$ writes, "First of all, I would just like to state that this is the first time I've read the primary text and turned to the secondary text with an understanding of the former that was RIGHT ON!" Michala subsequently writes, "I have to start by

2 I have introduced minor edits into the blog posts for ease of reading and focus. For example, I do not include ellipses where I have skipped over a few words or sentences to get to the main point. I have also corrected spelling mistakes, as the blog posts reflect unedited writing. I have not, however, corrected diction, usage, or capitalization patterns to conform with professional scholarly standards, as I want readers to be able to access the students' voices in as authentic terms as possible.

3 I have changed the names of all students to preserve anonymity and their privacy. 
congratulating Georgia. ... Her 'ah-ha' moment was very well expressed through her post, and I enjoyed reading about it. It's fun to see that we're all progressing in our journey to understand the world of Talmud study." Their joy is palpable. Caitlin echoes these sentiments in her post, "I would say that, by far, this was my most enjoyable reading. I felt that I somewhat experienced a partial review of everything I have learned. I could see the beit midrash of the Amoraim come to life [in the argument between Rava and Abaye]."

\section{Big Picture versus Textual Details}

The accomplishments at semester's end did not come easily to my students. Culturally conditioned habits developed in other classroom settings and when reading other literatures did not necessarily serve them well when reading talmudic texts. They had to become aware of what they were doing instinctively that was not productive for Talmud if they were deliberately to cultivate an alternate set of reading practices. One habit that students grappled with is the tendency to gloss over details in the hope of stabilizing meaning by detecting an overarching narrative. Listen to Georgia as she begins to recognize what she is doing and how this glossing over does not serve her well when reading talmudic materials for this course. Her post was composed one month into the semester. (I have added numbers to her text that clarify the order in which she performed the tasks she set for herself as she worked through the reading. Note that task 5 is mentioned after task 6. The numbers correspond to the order in which she performed the tasks, not the order in which she narrates them):

(1) The first thing I did when reading B. Bava Metsia 59b was quickly read through the passage in an attempt to get the "gist" of what it was saying. I was startled by how I wanted to know what the text meant right then and there after breezing through it only once. (2) Then, I read through it much slower. I read each paragraph carefully, restating each sentence's meaning in my head before moving onto the next sentence, and then restating each paragraph's meaning before moving onto the next. If I couldn't get the full meaning of the paragraph or didn't understand a sentence after trying to re-word it to myself, I would look to the 
next paragraph or sentence to see if it could shed light on the part I was confused by. (3) Then, I wrote down any questions I had for that section or new questions for other sections, in light of the information I had just read. (4) Finally, I read the passage in its entirety to see if I got answers to my questions. Halfway through this step-right after re-reading the whole passage and at the start of processing through it - my friend texted me to say he was in my parking lot waiting to pick me up for dinner. So-more so by chance than by choice-(6) I was forced to return to the text a few days later, at which time (5) I read the other primary texts and the secondary source.

The more effective steps in my learning process included the second step (2) of reading really slowly, trying to gain understanding for each piece of information before moving to the next, as well as the last (unintentional) step (6) of returning to the piece at a later time and re-reading it alongside prior notes and questions. I learned that reading a passage quickly to get the gist of it before rereading it slower (step 1) didn't really aid my learning. Though I gained more understanding of the text by re-reading it slower the second time (step 2), I don't think that the text really started to make sense until I re-read it a third time that day (step 4), and a fourth time today (step 6). I think this is because I only could understand the whole of the text by first understanding it in bits and then combining [those] bits together slowly to form a whole. Additionally, I had read the secondary source packet (step 5) the fourth time (step 6) I read it and had also given my brain a break from strongly focusing on the text, both of which gave me a clearer head while reading. This has made me very self-aware as a learner, as I've found myself trying to implement what worked well and avoid what didn't work well in readings for other classes this week.

Georgia's first instinct was to read the text in a superficial manner to "get the gist." She hopes to gain a sense of the whole by reading quickly and glossing over details. She reasons that if she can identify an overarching narrative or structure, she will know what to do with the myriad of details she encounters. While this assumption may serve her well with other literatures, it frustrates her when reading this talmudic passage: "I was startled by how 
I wanted to know what the text meant right then and there, after breezing through it only once". Georgia finds that she cannot get a sense of the whole without painstakingly attending to details. She does much better when she "reads each [sentence and] paragraph carefully," making sure not to move to the next sentence or paragraph until she has a grasp of the current one. She finds that she can "only understand the whole of the text by first understanding it in bits and then combining bits together slowly to form a whole." Georgia is aided in her ability to fit the bits into a whole by having read the secondary source. Reading the secondary source eliminates many potential ways to configure the bits and offers a few suggestive patterns. In the end, Georgia achieves a sense of the whole, but she has to work in unfamiliar ways.

The final paper of another student reflects on an initial resistance to reading slowly and paying attention to details. Like Georgia, Anna finds it helpful to review the text several times.

I had to adapt my reading strategies in order to better understand the [Mishnah]. Taking the time to [look up the biblical sources of a mishnah] was new for me. I also realized that I needed to slow down and read deliberately and with intention. Full comprehension was not attainable if I was reading under a time constraint or if I was distracted. Under those circumstances, I would read on a superficial level, in which simply getting the words into my head was my main goal. Realizing this flaw forced me to create a new strategy that involved multiple readings, each with a different focus. The first reading was the same, in that I read for content alone, but in addition, I would read a second, if not also a third, to focus on questions such as: Why is this information grouped together? What is the significance of word choice and repetition? What has been extrapolated from the biblical text?

Anna finds that she has to "adapt [her] reading strategies" in order to make sense of the Mishnah. Her observation that reading on a "superficial level" is nothing more than "getting the words into my head" echoes Georgia's sense of the futility of quickly skimming through the text. Though one hears hints of mild resistance to the practice of looking up the biblical sources of the Mishnah, Annass reading is enriched by engaging such details. Like Georgia, Anna also benefits from multiple readings, each one achieving a different 
degree of integration. Only on the second or third time through the text can she address questions that reveal what is interesting about the passage: "Why is this information grouped together? What is the significance of word choice and repetition? What has been extrapolated from the biblical text?"

Michala also has to fight a natural tendency to skim over details that slow her down. The following post was composed about three-quarters of the way through the course:

For my reflection, I decided to address a problem that I tend to have with the primary readings in this course as someone who comes from an Episcopalian faith. Plainly put, I don't usually know what I'm reading. I might understand what I'm reading about, but I often make it through an entire piece without even knowing what I'm reading. In the Episcopal Church, we work with the Bible and the Book of Common Prayer. When it comes to studying, the Bible is the only text we focus on. Judaism has much more material, all of which is referred to by different names. I'm still training myself to take the time to figure out what I'm reading when I sit down with a primary text from Judaism as opposed to immediately jumping into the content.

When I first sat down with the syllabus, I noted the assigned text, "m. Shevu'ot, chapter 3." I knew that the ' $m$ ' signified this piece to be part of the Mishnah. This might seem insignificant, but considering we've been looking at texts that start with familiar names like "Genesis" or "Exodus" [as in Genesis or Exodus Rabbah], as well as unfamiliar things like "b. Baba," a little " $m$ " can really help differentiate texts. I flipped back to my notes from our last class and refreshed my memory on the differences between midrash and mishnah. We have been reading a lot of midrash, especially in preparation for our papers, so I wanted to make sure I was clear on the difference. I recalled from my notes that the Mishnah [had] a topical arrangement [that] brought together all the verses on a particular topic from many different sources. So, in our reading for today, I could expect one main topic as the subject and explanations and clarifications brought together by many sources. I noted from the primary packet that the Shebuoth was part of the Tractate Nezikin. A quick Google search revealed that this was part of the Mishnah's order on civil damages. 
In the first paragraph, Michala admits that she often skims over cumbersome information. It "takes time to figure out what [she's] reading," and until now, she has not felt that time spent in this manner is a worthwhile investment. Underlying her disinclination to clarify the name of the document from which she reads is her assumption that such details are irrelevant to understanding the text properly. Michala accounts for her inattention to detail by referring to a feature of her religious upbringing. When people engage text in her church, they do not need to pay attention to which book they are reading, as all readings are drawn from the same book ("the Bible is the only text we focus on"). Like Georgia and Anna, Michala resists taking the time to focus on details that initially appear trivial. She finds that she is well served, however, when she slows down and pays attention to the "little m." She returns to her notes from the previous class to recall salient features of the Mishnah-for example, that it had a topical arrangement that beneficially informs her subsequent reading of the primary sources ("I could expect one main topic as the subject").

My last student example, Derek, likewise develops as a reader of Talmud when he shifts his gaze from the "big picture" to smaller units of text:

I came into this class with the most questions about the process of talmudic argumentation. I had read passages from Talmud in previous classes, and had looked at Mishnah and Baraitas. However, whenever I attempted to approach one of these passages, I was always driven towards a summary or some other abridgement.

Unlike a number of other students in the class, Derek had enough prior exposure to Talmud to have a particular interest in "the process of talmudic argumentation." Derek's previous experiences, however, did not give him reading strategies to make sense of argumentation. One guesses he may have encountered Talmud in an excerpted format, perhaps in the form of pithy wisdom sayings or sage stories. Derek shares with the other students an initial resistance to focusing on details. The fact that he "was always driven towards a summary or some other abridgement" reflects his assumption that a text is most effectively amalgamated when it is stripped of its particularities and reframed in generic terms. Derek does not seem to know what to do 
with textual details aside from moving quickly past them as distractions to a higher understanding. He grows as a reader, however, when he learns to focus on, rather than gloss over, textual details:

What was pivotal for me was the Boyarin article. Specifically, Daniel Boyarin states that the semiotic elements of the Torah "function for the rabbis much as words do in ordinary speech." This really illustrated an important reading strategy for the rabbis, atomization. It helped me to think of the Torah, not as a collection of tales from different authors nor as a linear and coherent narrative, but as a series of passages, which Boyarin describes as being like a dictionary. Each phrase from the Torah can operate as an independent lexeme in Midrash and Mishnah.

This passage captures Derek in the process of learning to see biblical verses through the lenses of the rabbis "as a series of passages" that (in Boyarin's words) "function for the rabbis much as words do in ordinary speech." ${ }^{4}$ Mastering the rabbinic genre of midrash means learning to see the Torah through the eyes of the rabbis. Derek observes that the rabbis atomize biblical verses and then combine the atomized bits so that each "operate[s] as an independent lexeme in Midrash and Mishnah." The atomized bits become the "words" of rabbinic discourse. For Derek, reading Torah like a rabbi entails engaging textual details in a new way. Textual details are no longer trivial data to be subordinated to a larger narrative framework ("tales" or "a linear and coherent narrative"). In order to experience fragments of biblical verses as the building blocks of rabbinic discourse, Derek must attend to, rather than gloss over or reduce, their particularity.

Each of these students initially resists focusing on textual details. They regard textual detail as something to be transcended, at best, and a minor nuisance to be quickly dispensed with, at worst. Instinctively, they find it easier to read for big ideas and themes. Each finds, however, that making sense of midrash, Mishnah, and Talmud requires giving into, rather than fighting, the details. A usable sense of the whole cannot be achieved unless they engage and address textual detail.

4 Daniel Boyarin, Intertextuality and the Reading of Midrash (Bloomington: Indiana University Press, 1990), 28. 


\section{The Fallacy of One Right Answer and the Importance of "Process"}

A second challenge that my students faced came from the assumption that texts have one correct meaning and from using their instinct to organize reading around the task of finding that one meaning. Reading in this manner did not position students to make sense of the texts easily. In reviewing Michala's mid-semester blog post, one can see her reading of midrash is structured as a quest for the right answer:

I was confused by Genesis R[abbah] 1.4. This passage is discussing whether the Torah or the Throne of Glory was created first. Many opinions about the correct answer are expressed through quotes. However, I simply don't understand which one is determined to be the right one. Is there a right answer?

Michala expects her reading of the midrash to resolve into a single "correct" view. She effectively identifies the passage's subject matter (the place of theTorah and the Throne of Glory in the order of creation), but is less successful at understanding the purpose of the midrash's discussion. Assuming that the text aims to convey a "correct answer" to readers, she is frustrated that she cannot discern it. Eventually, Michala learns to structure her reading of midrash around the insight it provides into rather than the answer it offers about biblical verses. In this excerpt from her final paper, she explains how she was able to move beyond the frustration expressed above:

In lecture, I was introduced to [the idea that] multiple answers do not cloud one's understanding, as I had originally thought, but rather provide readers of Midrash with different ways of making sense of the material. My notes serve as evidence of the moment during class when the light bulb went off-There is no accepted view! But now we know the text in a deeper way. So the goal is to know the text better.

In Michala's new way of thinking, midrash helps the reader "know the [biblical] text in a deeper way." Michala makes peace with the fact that the passage does not make clear whether the Torah or the Throne of Glory was created first, because she realizes midrash offers her something 
else instead. It familiarizes her with the biblical verses that support each position, which she learns to read in new ways. Though she formerly glossed over certain details as insignificant, she now regards them as the basis for each unique position. Michala no longer reads midrash to learn answers. Her new orientation is to use midrash to "know the [biblical] text better."

Anna's learning trajectory is also shaped by an initial assumption, which she must first recognize and then suspend-that texts have a single meaning readers should acquire in the act of reading. Like Michala, she writes in her final paper that she "had to embrace [the fact] that sometimes there is no right answer to a question and that significance is found in the process of [seeking] explanation." In her new way of thinking, reading stimulates a "process of explanation." As she formulates the matter, the goal of reading is not acquiring a thing ("the answer"), but having an experience ("a process"). In the final papers, several students (including Anna and Michala) retrospectively realize and adopt a new found focus on "process" as central to their eventual success, as opposed to what they variously call "answers," "content," and "literal meaning." Michala, whose frustration is evident in the mid-semester blog post we read above, also resolves her problem by shifting the focus of her reading from finding "answers" to experiencing "process." In the final paper excerpted above, she distances herself from her former orientation and explains that "the goal is not always to get a clear answer. When it comes to Talmud study, the point is to interact with the Torah in a special way, to see the beauty in many different perspectives, and to understand the thought processes involved in arriving at those perspectives.” Michala's new perspective is that one reads to "understand the thought processes" of the sages whose "conversations" are recorded in the Talmud. Reading is now about recreating and experiencing anew a conversation implied by the Talmud's words. The words do not carry meaning in and of themselves. Instead, they are clues from which she recreates what she, later in the paper (and not quoted in this chapter), calls the "original 'thrust and parry' that took place in the study houses."

Excerpts from Caitlin's final paper eloquently and passionately identify the same shift in perspective-from a focus on "content" to one on "process"- as 
central to her success as a reader of Talmud. The paper's introduction sets out basic ideas that she explores in the body of the paper:

Coming into the course, I failed to realize that the course objective was to understand the Talmud's study process just as much as the Talmud's content. I focused on the historical and intellectual framework surrounding the primary texts we were examining. My failure to grasp the full objective skewed my encounter with all the materials up until when midrash was introduced. When midrash was presented as an intellectual disposition from which the rabbis read the Torah, as well as a literary record of that activity, my eyes for the Talmud were opened and I finally saw it for what it was: a beautiful literary record of the live arguments that went on in the Amoraic beit midrash, arguments that went on in order to keep Written Torah alive through a continual creation of Oral Torah.

Here, Caitlin distinguishes between two approaches to reading: one that seeks to understand the text's "study process" and the other approach, only its "content." Since the course is called Introduction to Talmud, she, as a student, expects it to familiarize her with the Talmud's content, and, initially, she orients her study toward that goal. By focusing on the "historical and intellectual framework surrounding the primary texts," she engages Talmud through the familiar paradigm of its content. By semester's end, however, she approaches the Talmud with a different end in mind. Seeing it now as a "literary record of live arguments," she seeks to replicate the rabbis' experience as thinkers, readers, and arguers in their own right. Adopting the "disposition from which the rabbis read the Torah" enables her to think the thoughts that they thought. Her new approach focuses on the "Talmud's study process" (i.e., the study process that lies behind the text) over and against its content. In the body of the paper, Caitlin returns to this key moment of insight:

Then, on the day, in the class, in the very moment that Professor Alexander explained midrash as a "literary record of the intellectual activity of reading in a midrashic way," the Talmud and the activity of Talmud study 
was forevermore transformed in my heart and mind; in that one moment, it all came alive, and I saw all the puzzle pieces fall together (Cox, notes). For the first time in the course, I was freed to fully to see what we were doing with our class: we were studying a record of a form of study. Unlike my other academic classes, we did not have to take sides and pick a perspective from within a debate and argue why one [view] was right over another.

The unstated question that Caitlin grapples with here is, "What is a text and to what does it point?" In other classes, texts inform her about issues that can be debated. She learns in those classes more about the issues by "picking a perspective and arguing why it is right." There, the goal is to understand "the thing," that is, the issues, to which the text points. When texts point to things, they are ontologically singular. That is why Caitlin is instructed to pick only one perspective to argue. The instruction to argue a single perspective resonates with Michala and Anna's preoccupation with the task of identifying the correct answer. They too expect texts to point to a single thing, "the answer." My course offers Caitlin a different way to think about texts. According to the new paradigm, texts point to an "intellectual activity." The delight in her voice is palpable as she realizes, "we were studying a record of a form of study." The implication here is that in class we were not studying a subject, informational content, or a perspective that could be held, acquired, or disputed. Rather, we were engaging in an experience that consisted of reliving the rabbis' study process.

\section{Conclusion}

The students whose voices appear in this chapter embraced and succeeded at the assignments that emphasized "learning how to learn." They used the blog posts and their final papers to cultivate awareness of both habits and assumptions that shape them as readers. For these students, the sixth component of Fink's taxonomy of significant learning experiences worked in conjunction with his other components in a mutually reinforcing 
manner. Students came to care about the subject matter. Recall Michala's enthusiasm for Georgia's success with her "Ah-ha! moment" and the success of the entire class at the end of the semester, as they followed each other "on-blog." Students also connected what they were doing in this course to work from other courses, as we saw in an early blog post from Georgia, who said, "I've found myself trying to implement what worked well and avoid what didn't work well in readings for other classes this week." And students mastered foundational knowledge and learned to apply it. Students also learned about themselves, as becomes apparent in a last excerpt of Anna's final paper at the conclusion of this essay.

Collectively, the student reflections cited in this chapter offer a relatively coherent account of some of the cultural assumptions about texts and reading that cause difficulties for liberal art students who are learning to read Talmud for the first time. My students at the University of Virginia learned about what they intuitively focus on "seeing" when they read a text (an overarching narrative) and what they assiduously ignore (textual details). They also learned about what they expected a text to provide them (answers or content, as opposed to access to a study process). Armed with increased alertness, curiosity, and a newly found respect for how to read, these students were able to self-intervene and adopt assumptions about texts and reading that are better suited to interact productively with Talmud. They came to understand that when reading Talmud they were not aiming to achieve the same things as when reading other literatures.

As is inevitable, of course, not all students in the course were as strong as the ones featured in this chapter, and not all students were enamored with this approach to teaching Talmud. One disgruntled student wrote in the anonymous online evaluations that "the central conceit of self-evaluation and changing the way we thought seemed grandiose and overblown, and the results were completely underwhelming. I would have learned way more about Talmud from a traditional lecture." These reservations notwithstanding, on the whole, students found the course worthwhile. When asked by the online course evaluation system to reflect on the statement "I learned a great deal in this course," $85 \%$ of students indicated that they "strongly agree," while the remaining 15\% indicated that they "agree." In 
comparable courses, ${ }^{5}$ only $53 \%$ state that they "strongly agree." By all measures, then, the course succeeded in effectively conveying course content to the students.

It is important to recognize that most of the students who took this course are not likely to find themselves reading Talmud again soon. For them, the course's value should not be measured in Talmud-specific terms, but in what they take forward. The final paragraph of Anna's final paper offers a nice summary of how an Introduction to Talmud course at a large public university can contribute to the broad goals of a liberal arts education:

I learned a lot this semester about how I personally read and relate to [all] texts. I began to develop a more patient understanding [of how to interact with texts; my new method is] characterized by multiple readings, synthesis, and dedication. I found that understanding does not come without effort, and that, sometimes, even effort cannot clear obscurities. I became more comfortable asking questions and admitting confusion, a skill I have never had to cultivate until this course. The most important skill I have acquired is the ability to see where my presuppositions are at odds with the methods I need to employ to analyze this material. Looking at a first-century or a seventh-century document through a twenty-first century lens prevented me from appreciating the perspective of authors of the [ancient texts]. It was hard to admit when my learning methods failed me, but it was with that failure that I reinvented my approach to the texts.

Anna's summary of what she learned from this course is firmly connected to the goals of the course. She developed habits of engaging texts that are particularly well suited to Talmud. For example, she formed an approach that includes "multiple readings, synthesis, and dedication" and she came to recognize where her "presuppositions are at odds ... [with] the perspective of the [ancient authors].” And yet, Anna frames her insights in a manner that

5 Evaluation data on all 3000-level courses taught during the semester in question at the University of Virginia's Department of Religious Studie was provided in conjunction with the results of my own course for comparative purposes. 
makes clear that these new habits have relevance moving forward. She has a new willingness to ask questions, admit confusion, and live with uncertainty, as when she admits that "sometimes even effort cannot clear obscurities." She displays a new disposition to learning that will inform how she engages difficult tasks in the future. Even though continued Talmud study may not be in the future of this environmental science major, the course has contributed to her intellectual formation. 